\title{
High central venous pressure is associated with prolonged mechanical ventilation and increased mortality after lung transplantation
}

\author{
D. V. Pilcher, MBBS, MRCPa \\ C. D. Scheinkestel, MBBS, FRACP, FJFICM ${ }^{\mathrm{a}}$ \\ G. I. Snell, MBBS, FRACPb \\ A. Davey-Quinn, MBBS, FRCA ${ }^{\text {a }}$ \\ M. J. Bailey, BSc(Hons), MSc (Statistics) ${ }^{c}$ \\ T. J. Williams, MBBS, FRACP
}

From the Departments of Intensive Care Medicine $^{\mathrm{a}}$ and Allergy, Immunology and Respiratory Medicine, ${ }^{\mathrm{b}}$ The Alfred Hospital, Prahran, Australia, and the Department of Epidemiology and Preventive Medicine, ${ }^{c}$ Monash University, Prahran, Australia.

Received for publication April 1, 2004; revisions received June 17, 2004; accepted for publication July 6, 2004.

Address for reprints: C. D. Scheinkestel, MBBS, FRACP, FJFICM, Department of Intensive Care, The Alfred Hospital, Prahran, VIC 3004, Australia (E-mail: cdsch@ connexus.net.au)

J Thorac Cardiovasc Surg 2005;129:912-8 $0022-5223 / \$ 30.00$

Copyright (C) 2005 by The American Association for Thoracic Surgery

doi:10.1016/j.jtcvs.2004.07.006
Background: Poor oxygenation might occur in transplanted lungs as a result of reperfusion injury and lack of lymphatic drainage. Low central venous and pulmonary capillary wedge pressures are advocated to reduce pulmonary edema and maximize oxygenation but might adversely affect cardiac index, circulation, and renal function.

Methods: Histories, intensive care unit charts, and donor data on 118 lung transplantations performed between 1999 and 2002 were retrospectively assessed. Multiple logistic regression analysis was performed on donor, recipient, operative, and intensive care unit parameters to determine the relationship of filling pressure (central venous and pulmonary capillary wedge pressures) to prolonged mechanical ventilation and outcome. The mean central venous pressure was used to divide patients into high and low central venous pressure groups, which were then compared to determine differences in outcome and complication rates.

Results: A high central venous pressure was found to be associated with prolonged mechanical ventilation (odds ratio, 1.57; 95\% confidence interval, 1.13-2.20; $P=$ .008). After removing the effect of poor myocardial function by excluding patients with low cardiac index $\left(<2.2 \mathrm{~L} \cdot \min ^{-1} \cdot \mathrm{m}^{-2}\right)$ and high inotrope requirement $(>10$ $\mu \mathrm{g} / \mathrm{min}$ ), central venous pressure remained associated with prolonged mechanical ventilation (odds ratio, 2.31; 95\% confidence interval, 1.31-4.07; $P=.004$ ). Duration of ventilation $(P<.001)$, intensive care unit mortality $(P=.02)$, hospital mortality $(P=.09)$, and 2-month mortality $(P=.02)$ were higher in patients with central venous pressures of greater than $7 \mathrm{~mm} \mathrm{Hg}$. There was no evidence of complications caused by hypovolemia in the low $(\leq 7 \mathrm{~mm} \mathrm{Hg})$ central venous pressure group, who had lower inotrope requirements $(P=.02)$ and lower creatinine levels $(P=.013)$.

Conclusions: A high central venous pressure was associated with adverse outcomes after lung transplantation.

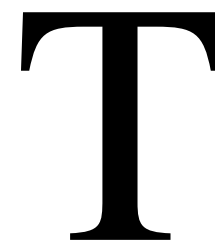

ransplantation is an established treatment for end-stage pulmonary vascular and parenchymal disease. Perhaps the most important factor complicating the early postoperative period is reperfusion pulmonary edema, which is reported in $10 \%$ to $35 \%$ of cases. ${ }^{1-4}$ The transplanted lung is at risk of this because of a lack of lymphatic drainage and inflammatory insults, such as infection-aspiration in the donor, direct pulmonary trauma, and inflammatory cytokine release associated with 
TABLE 1. Multivariate analysis of factors associated with prolonged mechanical ventilation for all patients

\begin{tabular}{lccc}
\hline & \multicolumn{3}{c}{ All Patients (n = 118) } \\
\cline { 2 - 4 } & Odds ratio & $\mathbf{9 5 \%}$ Cl & $\boldsymbol{P}$ value \\
\hline CVP (days 1-3) & 1.57 & $1.13-2.20$ & .008 \\
$\mathrm{PaO}_{2} / \mathrm{FIO}_{2}$ (day 1) & 0.989 & $0.980-0.998$ & .020 \\
$\mathrm{APACHE}$ II score & 1.21 & $1.08-1.36$ & .001 \\
\hline
\end{tabular}

$\mathrm{Cl}$, Confidence interval; $\mathrm{CVP}$, central venous pressure; $\mathrm{FlO}_{2}$, fraction of inspired oxygen.

brain death, explantation, and reperfusion. ${ }^{5,6}$ Although disputed, preferential cardiac output through the first implanted lung during bilateral sequential transplantation has also been proposed as a risk factor for reperfusion injury., Thus, edema might occur through a combination of increased hydrostatic forces and increased capillary permeability. ${ }^{9,10}$

Protocols for routine postoperative care specify that filling pressures, such as pulmonary capillary wedge pressure (PCWP) and central venous pressure (CVP), should be kept low to minimize reperfusion pulmonary edema. ${ }^{11} \mathrm{~A}$ theoretical disadvantage is that this might lead to hypovolemia, renal dysfunction, and increased inotrope requirements. There is, however, no evidence base to support this. The primary aim of our study was to determine whether such a relationship existed and to determine whether patients had evidence of complications arising from this relationship.

\section{Methods}

\section{Patient Population}

From the beginning of July 1999 to the end of June 2002, a total of 128 lung transplantations were performed at the Alfred Hospital. Complete information was available for 118 of the patients: 61 bilateral sequential lung transplant recipients and 57 single lung transplant recipients.

\section{Primary Outcome}

The primary outcome examined was prolonged mechanical ventilation (PMV), which is defined as the need for mechanical ventilation on the third postoperative day. Patients who were extubated but needed reintubation before day 3 and patients who died before day 3 were also included in the PMV group. Intensive care unit (ICU) mortality, 30-day mortality, hospital mortality, and overall survival time were noted. The mean CVP $(7.2 \mathrm{~mm} \mathrm{Hg})$ for the group was then used to divide patients into high $(>7 \mathrm{~mm} \mathrm{Hg}$ ) and low ( $\leq 7 \mathrm{~mm} \mathrm{Hg}$ ) CVP groups to compare their outcomes.

\section{Donor Factors}

Donor assessment was according to previously published guidelines. $^{12}$ Standard donor selection criteria were age less than 55 years, ABO compatibility, a smoking history of less than 20 pack-years, a clear chest radiograph, absence of chest trauma, no

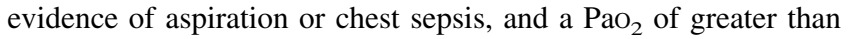

TABLE 2. Multivariate analysis of factors associated with prolonged mechanical ventilation after exclusion of patients with low cardiac output or high inotrope dosage

\begin{tabular}{llcc}
\hline & \multicolumn{3}{l}{$\begin{array}{l}\text { Patients with cardiac index }>\mathbf{2 . 2} \mathbf{L} \cdot \mathbf{m i n}^{-\mathbf{1}} . \\
\mathbf{m}^{-\mathbf{2}} \text { and inotropes } \leq \mathbf{1 0} \boldsymbol{\mu g} / \mathbf{m i n}(\mathbf{n}=\mathbf{9 9})\end{array}$} \\
\cline { 2 - 4 } & $\begin{array}{l}\text { Odds } \\
\text { ratio }\end{array}$ & $\mathbf{9 5 \%} \mathbf{~ c ~}$ & $\boldsymbol{P}$ value \\
\hline $\mathrm{CVP}$ (days 1-3) & 2.31 & $1.31-4.07$ & .004 \\
$\mathrm{PaO}_{2} / \mathrm{FIO}_{2}$ (day 1) & 0.987 & $0.975-1.00$ & .044 \\
$\mathrm{APACHE}$ II Score & 1.16 & $0.99-1.35$ & .055 \\
\hline
\end{tabular}

$\mathrm{Cl}$, Confidence interval; $\mathrm{CVP}$, central venous pressure; $\mathrm{FlO}_{2}$, fraction of inspired oxygen.

$300 \mathrm{~mm} \mathrm{Hg} . \mathrm{PaO}_{2}$ was measured on $100 \%$ fraction of inspired oxygen $\left(\mathrm{FIO}_{2}\right)$ and $5 \mathrm{~cm} \mathrm{H}_{2} \mathrm{O}$ positive end-expiratory pressure (PEEP). There were 105 donors for 128 recipients. Of these, 13 were older than 55 years, and 3 had $\mathrm{PaO}_{2}$ values of less than 300 $\mathrm{mm} \mathrm{Hg}$. Lung procurement and preservation followed a standard protocol, with cold modified Euro-Collins solution for antegrade flushing. Prostacyclin (Flolan, Wellcome) was also infused at 40 to $80 \mathrm{ng} \cdot \mathrm{kg}^{-1} \cdot \mathrm{min}^{-1}$ for approximately 10 minutes before crossclamping the pulmonary artery. Donor variables analyzed were age, sex, $\mathrm{PaO}_{2}$, history of smoking, and inotrope use.

\section{Recipient Factors}

Recipient selection for transplantation was according to previously published guidelines. ${ }^{13}$ Recipient factors analyzed were sex, age, diagnosis, and preoperative creatinine level. Diagnoses were coded as cystic fibrosis, primary pulmonary hypertension, interstitial lung disease, chronic obstructive pulmonary disease, and "other" for the remaining patients.

\section{Operative Factors}

The technical details of lung transplantation have been previously described. ${ }^{14}$ A pulmonary artery flotation catheter (Edwards Lifesciences, Irvine, Calif) was inserted in each recipient preoperatively to monitor cardiac output, pulmonary artery pressures, CVP, and PCWP. This was then used to guide operative anesthetic management and remained in situ in the ICU. Operative factors analyzed were incidence and duration of cardiopulmonary bypass, ischemic time for the organs, and procedure type (single-bilateral transplantation). In cases in which double-lung transplantation was undertaken, the mean ischemic time of the 2 lungs was analyzed.

\section{ICU Factors}

ICU management was aimed at ensuring the adequacy of end-organ perfusion. Although maintaining low filling pressures (PCWP of $\leq 10$ $\mathrm{mm} \mathrm{Hg}$ and CVP of $\leq 7 \mathrm{~mm} \mathrm{Hg}$ ) was usually a target, it was not aggressively pursued. Inhaled nitric oxide (at $20 \mathrm{ppm}$ ) was used if there was increasing pulmonary artery pressure or decreasing oxygenation. Independent lung ventilation and extracorporeal membrane oxygenation were used if required. The immunosuppressive regimen has been published previously. ${ }^{15}$ Maintenance comprised cyclosporine (INN: ciclosporin; initially aiming for trough levels of 300-450 $\mu \mathrm{g} / \mathrm{L})$, azathioprine $\left(1.5-2 \mathrm{mg} \cdot \mathrm{kg}^{-1} \cdot \mathrm{d}^{-1}\right)$, and prednisolone $(0.15$ 
TABLE 3. Comparison of patients with CVPs of $7 \mathrm{~mm} \mathrm{Hg}$ or less with patients with CVPs of greater than $7 \mathrm{~mm} \mathrm{Hg}$

\begin{tabular}{|c|c|c|c|}
\hline $\begin{array}{l}\text { Donor, recipient, and operative } \\
\text { variables }\end{array}$ & $\begin{array}{c}\text { CVP } \leq 7 \mathrm{~mm} \mathrm{Hg} \\
(\mathrm{n}=56)\end{array}$ & $\begin{array}{c}\text { CVP }>7 \mathrm{~mm} \mathrm{Hg} \\
\quad(\mathrm{n}=62)\end{array}$ & $P$ value \\
\hline \multicolumn{4}{|l|}{ Donor factors } \\
\hline Age (y) & $38 \pm 14$ & $35 \pm 15$ & .22 \\
\hline $\mathrm{PaO}_{2}(\mathrm{~mm} \mathrm{Hg})$ & $469 \pm 122$ & $462 \pm 90$ & .21 \\
\hline Female sex & $41 \%(n=23)$ & $40 \%(n=25)$ & .78 \\
\hline Smoking donor & $57 \%(n=32)$ & $47 \%(n=29)$ & .43 \\
\hline Donor taking inotropes & $80 \%(n=45)$ & $77 \%(\mathrm{n}=48)$ & .62 \\
\hline \multicolumn{4}{|l|}{ Recipient factors } \\
\hline \multicolumn{4}{|l|}{ Diagnosis } \\
\hline CF (mean CVP $=7 \pm 3$ ) & $30 \%(\mathrm{n}=17)$ & $31 \%(n=19)$ & 67 \\
\hline COPD (mean CVP $=7 \pm 2$ ) & $59 \%(n=33)$ & $47 \%(n=29)$ & .26 \\
\hline $\mathrm{PPH}($ mean CVP $=11 \pm 4)$ & $0 \%(\mathrm{n}=0)$ & $5 \%(n=3)$ & .28 \\
\hline ILD (mean CVP $=7 \pm 2$ ) & $11 \%(n=6)$ & $13 \%(\mathrm{n}=8)$ & .66 \\
\hline Other (mean CVP $=10 \pm 2$ ) & $0 \%(\mathrm{n}=0)$ & $5 \%(n=3)$ & .28 \\
\hline Female sex & $34 \%(n=19)$ & $52 \%(n=32)$ & .12 \\
\hline Age (y) & $45 \pm 16$ & $43 \pm 14$ & .23 \\
\hline Preoperative creatinine ( $\mu \mathrm{mol} / \mathrm{L})$ & $67 \pm 22$ & $73 \pm 28$ & .44 \\
\hline \multicolumn{4}{|l|}{ Operative factors } \\
\hline Single lung transplantation & $57 \%(\mathrm{n}=32)$ & $40 \%(n=25)$ & .11 \\
\hline Proportion requiring CPB & $2 \%(\mathrm{n}=1)$ & $13 \%(\mathrm{n}=8)$ & .09 \\
\hline Duration of CPB (min) & $149 \pm 0$ & $180 \pm 69$ & .17 \\
\hline Ischemic time (min) & $374 \pm 133$ & $365 \pm 133$ & .40 \\
\hline
\end{tabular}

Prevalence data are presented as a percentage of the total in each group. Continuous variables are presented as means \pm SD. CVP, Central venous pressure; $C F$, cystic fibrosis; $C O P D$, chronic obstructive pulmonary disease; $P P H$, primary pulmonary hypertension; ILD, interstitial lung disease; $C P B$, cardiopulmonary bypass.

$\mathrm{mg} \cdot \mathrm{kg}^{-1} \cdot \mathrm{d}^{-1}$ ). All patients received prophylactic antibiotics on the basis of known or suspected recipient and donor microbiology results. Ganciclovir (initially at $10 \mathrm{mg} \cdot \mathrm{kg}^{-1} \cdot \mathrm{d}^{-1}$ ) was used where indicated as prophylaxis against cytomegalovirus.

ICU management variables were recorded for each 24-hour period after the operation. Cardiovascular variables analyzed were cardiac index (in liters per minute per meter squared) PCWP (in millimeters of mercury), CVP (in millimeters of mercury), and inotrope dosage. The mean value for day 1 and the mean value for days 1 to 3 were included in the multivariate analysis. Inotrope doses were recorded hourly in micrograms per minute. Epinephrine and norepinephrine doses were added together for the final inotrope dose. Other vasoactive drugs, such as dopamine $(\mathrm{n}=11)$, milrinone $(n=2)$, dobutamine $(n=2)$, and isoprenaline $(n=1)$, were rarely used and not included in the analysis. Respiratory variables analyzed were worst $\mathrm{PaO}_{2} / \mathrm{FIO}_{2}$ ratio in each 24-hour period, mean level of PEEP over each day, and duration of mechanical ventilation. $\mathrm{PaO}_{2} / \mathrm{FIO}_{2}$ ratios were recorded independently from those used to calculate the Acute Physiology and Chronic Health Evaluation (APACHE II) score. Renal factors included worst creatinine level during ICU stay and mean fluid balance over the first 3 days. The APACHE II scores for each patient and APACHE II-derived predicted mortality were also recorded.

\section{Statistical Analysis}

All analyses were performed with SAS version 8.2 software (SAS Institute Inc, Cary, NC). Each variable was analyzed as a separate risk factor for the outcome by comparing patients who required PMV with those who did not.
All data were assessed for normality and log-transformed where appropriate. Univariate analysis was conducted by Student $t$ tests, $\chi^{2}$ tests for equal proportion, and Wilcoxon rank-sum tests where appropriate. Multivariate models were constructed by a stepwise selection procedure and then validated by a backward elimination procedure. All donor, recipient, operative, and ICU variables were used to build a multivariate model to determine factors associated with PMV. The inclusion of statistically nonsignificant but clinically relevant variables, such as the diagnostic categories, did not alter the final model. A final validation process involving an assessment of clinical plausibility was also incorporated. Information is presented as means with SDs for normally distributed data and medians with interquartile ranges for nonparametric data.

\section{Results}

Complete information was available for 118 of the 128 lung transplantations performed at the Alfred Hospital from the beginning of July 1999 to the end of June 2002. Twentyseven patients needed PMV. This included 4 patients who were extubated but required reintubation before day 3 and 2 patients who died before day 3. Of the missing 10 patients, 3 required PMV. All 3 left the ICU alive, but 1 died before leaving the hospital.

Multiple logistic regression analysis was used to incorporate factors associated with PMV at a univariate level into a multivariate model. This confirmed that a high CVP (over 


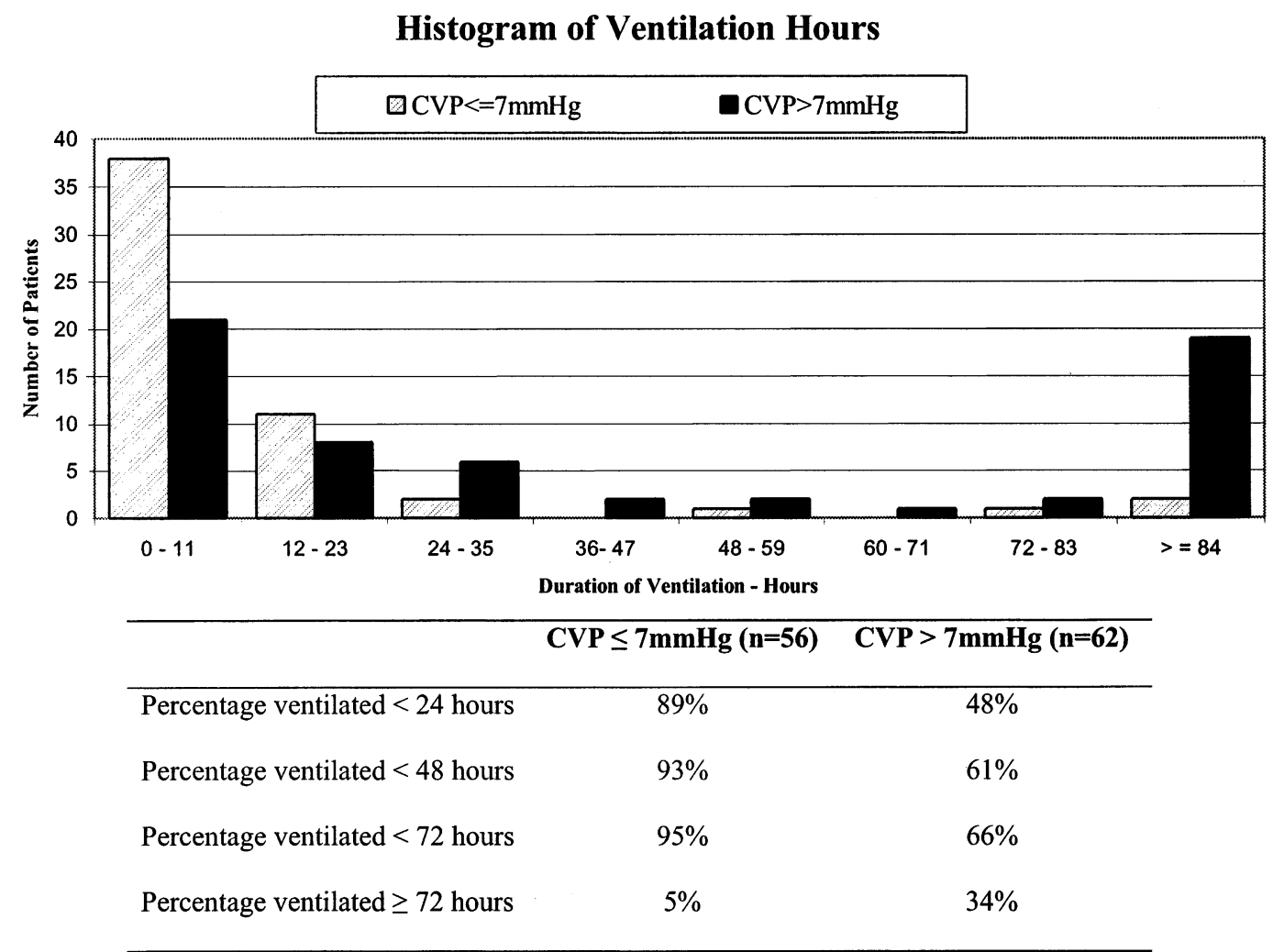

Figure 1. Histogram of ventilation hours.

TABLE 4. Comparison of outcomes between patients with CVPs of $7 \mathrm{~mm} \mathrm{Hg}$ or less and patients with CVPs of greater than $7 \mathrm{~mm} \mathrm{Hg}$

\begin{tabular}{|c|c|c|c|}
\hline & $\begin{array}{c}\text { CVP } \leq 7 \mathrm{~mm} \mathrm{Hg} \\
(\mathrm{n}=56)\end{array}$ & $\begin{array}{c}\text { CVP }>7 \mathrm{~mm} \mathrm{Hg} \\
(\mathrm{n}=62)\end{array}$ & $P$ value \\
\hline Prolonged mechanical ventilation & $4 \%(n=2)$ & $40 \%(n=25)$ & $<.001$ \\
\hline Duration of ICU stay $(d)$ & $3(2-3)$ & $5(3-7)$ & $<.001$ \\
\hline Duration of hospital stay: survivors (d) & $19(16-25)$ & $27(16-46)$ & .02 \\
\hline ICU mortality & $0 \%(n=0)$ & $8 \%(n=5)$ & .02 \\
\hline Hospital mortality & $4 \%(n=2)$ & $13 \%(n=8)$ & .09 \\
\hline
\end{tabular}

Prevalence data are presented as a percentage of the total in each group. Continuous variables are presented as medians (interquartile ranges). CVP, Central venous pressure; $I C U$, intensive care unit.

days $1-3)$ was related to PMV $(P=.008)$. The only other 2 significant factors were a high APACHE II score $(P=.001)$ and a low $\mathrm{PaO}_{2} / \mathrm{FIO}_{2}$ ratio on day $1(P=.02$; Table 1$)$. Donor, recipient, and operative factors were not related to PMV. Although there was a tight correlation between the CVP and PCWP $(R=0.75, P<.0001)$, PCWP was not an independent predictor of PMV in the mechanical ventilation analysis. All further analyses were done with the CVP. The mean CVP (7.2 $\mathrm{mm} \mathrm{Hg}$ ) for the group was then used to divide patients into low $(\leq 7 \mathrm{~mm} \mathrm{Hg})$ and high $(>7 \mathrm{~mm} \mathrm{Hg})$ CVP groups to compare their outcomes.

The data were analyzed further to allow for the effect of factors that might influence the CVP, including mechanical ventilation, vasoconstrictor inotropes, and low cardiac output. PEEP was already included in the multivariate analysis as a significant variable in its own right. Despite a statistically significant difference in the level of PEEP between the groups $\left(4.8 \pm 2.2 \mathrm{~cm} \mathrm{H}_{2} \mathrm{O}\right.$ vs $\left.6.6 \pm 2.9 \mathrm{~cm} \mathrm{H}_{2} \mathrm{O}, P=.003\right)$, 


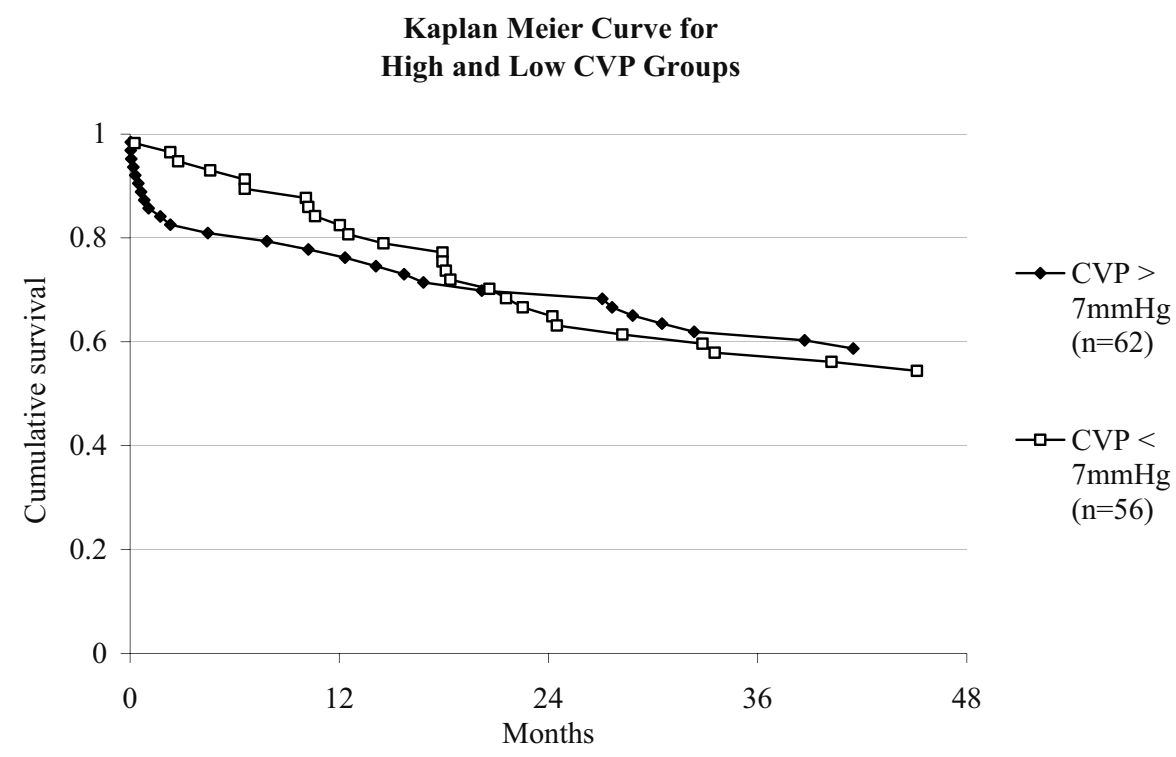

\begin{tabular}{lccc}
\hline Time & $\begin{array}{c}\text { Deaths } \\
\text { CVP } \leq \text { 7 } \mathbf{~ m m H g}\end{array}$ & $\begin{array}{c}\text { Deaths } \\
\mathbf{C V P}>\mathbf{7 ~ m m H g}\end{array}$ & pValue \\
\hline 2 months & $1 / 56$ & $10 / 62$ & 0.02 \\
6 months & $4 / 56$ & $12 / 62$ & 0.10 \\
1 year & $9 / 56$ & $14 / 62$ & 0.51 \\
4 years & $26 / 30$ & $26 / 33$ & 0.62 \\
\hline
\end{tabular}

Figure 2. Kaplan-Meier curve for high and low CVP groups. While patients with high CVPs had higher ICU mortality $(P=.02)$ and higher mortality at 2 months $(P=.02)$, their overall survival was not significantly different from those with low CVP $(P=.7)$.

PEEP was not an independent factor associated with PMV. After excluding 19 patients who had both a cardiac index of $2.2 \mathrm{~L} \cdot \mathrm{min}^{-1} \cdot \mathrm{m}^{-2}$ or less (10th percentile) and inotropes of greater than $10 \mu \mathrm{g} / \mathrm{min}$ (90th percentile), the CVP $(P=$ $.004)$ and $\mathrm{PaO}_{2} / \mathrm{FIO}_{2}$ ratio $(P=.044)$ remained significantly associated with PMV (Table 2). The APACHE II score was no longer significant, but the CVP increased in significance $(P=.004)$.

There were no differences in recipient, donor, or operative factors between the 2 groups (Table 3 ). More patients in the high CVP group needed PMV $(P<.001)$. The distribution curve of duration of ventilation for the high and low CVP groups is shown in Figure 1. Of the 27 patients who needed PMV, 25 had CVPs of greater than $7 \mathrm{~mm} \mathrm{Hg}$. The high CVP group had greater ICU mortality $(P=.02)$ and longer ICU stays $(P<.001)$, and survivors spent longer in the hospital $(P=.02)$. All 5 ICU deaths were in patients with CVPs of greater than $7 \mathrm{~mm} \mathrm{Hg}$ (Table 4). Of those who died before 2 months, 10 of 11 patients had CVPs of greater than $7 \mathrm{~mm} \mathrm{Hg}$, and all required PMV. Although patients with high CVPs had higher mortality at 2 months $(P=.02)$, their overall survival was not significantly different from that of those with low CVPs $(P=.7$, Figure 2$)$.

Patients with high CVPs had higher APACHE II scores $(P$ $=.004)$, higher inotrope requirements $(P=.04)$, and higher creatinine levels $(P=.001)$. There was a trend toward worse oxygenation (day $1, P=.06$; day $2, P=.05$ ) in those with high CVPs. There was no difference in the fluid balance or cardiac index between the 2 groups (Table 5).

\section{Discussion}

Low filling pressures (CVP and PCWP) are routinely advocated by most transplant centers to minimize pulmonary edema caused by reperfusion injury. ${ }^{11}$ Despite publication of risk factors for reperfusion injury, ${ }^{16} \mathrm{PMV},{ }^{17,18}$ and adverse early outcomes ${ }^{19}$ after lung transplantation, the influence of CVP or PCWP on outcome has not been clearly established. 
TABLE 5. Comparison of patients with CVPs of $7 \mathrm{~mm} \mathrm{Hg}$ or less with patients with CVPs of greater than $7 \mathrm{~mm} \mathrm{Hg}$

\begin{tabular}{|c|c|c|c|}
\hline ICU/physiologic variables & CVP $\leq 7 \mathrm{~mm} \mathrm{Hg}$ & CVP $>7 \mathrm{~mm} \mathrm{Hg}$ & $P$ value \\
\hline APACHE II score & $14 \pm 5$ & $18 \pm 7$ & .004 \\
\hline APACHE II predicted mortality & $15 \% \pm 11 \%$ & $23 \% \pm 20 \%$ & .02 \\
\hline \multicolumn{4}{|l|}{ Cardiovascular days 1-3 } \\
\hline CVP $(\mathrm{mm} \mathrm{Hg})$ & $5.0 \pm 1.5$ & $9.1 \pm 1.4$ & $<.001$ \\
\hline PCWP $(\mathrm{mm} \mathrm{Hg})$ & $8.4 \pm 2.2$ & $11.6 \pm 2.1$ & $<.001$ \\
\hline Cardiac index $\left(\mathrm{L} \cdot \mathrm{min}^{-1} \cdot \mathrm{m}^{-2}\right)$ & $3.6 \pm 0.5$ & $3.4 \pm 0.67$ & .12 \\
\hline Inotrope dose ( $\mu \mathrm{g} / \mathrm{min})$ & $1.3(0.3-2.8)$ & $2.4(0.3-5.7)$ & .04 \\
\hline \multicolumn{4}{|l|}{ Respiratory } \\
\hline Duration of ventilation (h) & $7(1-16)$ & $25(6-97)$ & $<.001$ \\
\hline Level of PEEP while ventilated $\left(\mathrm{cm} \mathrm{H}_{2} \mathrm{O}\right)$ & $4.8 \pm 2.2$ & $6.6 \pm 2.9$ & .003 \\
\hline $\mathrm{PaO}_{2} / \mathrm{FIO}_{2}$ ratio day 1 & $209 \pm 101$ & $180 \pm 110$ & .06 \\
\hline $\mathrm{PaO}_{2} / \mathrm{FlO}_{2}$ ratio day 2 & $272 \pm 102$ & $233 \pm 92$ & .05 \\
\hline Single-lung ventilation & $2 \%(\mathrm{n}=1)$ & $13 \%(n=8)$ & .03 \\
\hline ECMO & $0 \%(\mathrm{n}=0)$ & $5 \%(\mathrm{n}=3)$ & .09 \\
\hline Nitric oxide & $9 \%(n=5)$ & $19 \%(\mathrm{n}=12)$ & .11 \\
\hline \multicolumn{4}{|l|}{ Renal } \\
\hline Highest postoperative creatinine in ICU ( $\mu \mathrm{mol} / \mathrm{L})$ & $78 \pm 28$ & $108 \pm 58.3$ & .001 \\
\hline Incidence of dialysis & $5 \%(\mathrm{n}=3)$ & $10 \%(n=6)$ & .47 \\
\hline Fluid balance days $1-3(\mathrm{~mL})$ & $+780(-540$ to +1761$)$ & $+1365(-9$ to +2700$)$ & .32 \\
\hline
\end{tabular}

Prevalence data are presented as a percentage of the total in each group. Continuous variables are presented as means \pm SD or median (interquartile range) as appropriate. CVP, Central venous pressure; ICU, intensive care unit; PCWP, pulmonary capillary wedge pressure; PEEP, peak end-expiratory pressure; $\mathrm{FIO}_{2}$, fraction of inspired oxygen; ECMO, extracorporeal membrane oxygenation.

Our analysis confirms that a high CVP is associated with PMV. Our study is a retrospective analysis. It cannot definitively demonstrate causal relationships or define the effect of interventions. Patients with CVPs of greater than $7 \mathrm{~mm}$ $\mathrm{Hg}$ had longer lengths of stay (in ICU and in hospital) and had higher mortality (in ICU and at discharge from hospital). Ten of the 11 early deaths $(<2$ months) occurred in patients who had both high CVPs and needed PMV. However, there was no evidence of decreased long-term survival in patients with high CVPs.

Although CVP and PCWP are commonly used as indicators of volume status and cardiac preload, they are influenced by many factors. ${ }^{20} \mathrm{We}$ have attempted to eliminate the effect of poor myocardial function on the CVP by repeating the analysis after exclusion of patients with low cardiac indices or patients receiving high doses of epinephrine, norepinephrine, or both. Having done this, the relationship of CVP to PMV remained significant. The confounding effect of mechanical ventilation on the CVP cannot be fully excluded, but the degree is variable depending on the mode of ventilation, the level of PEEP, and the compliance of the respiratory system. ${ }^{21-23}$ To take this into account, PEEP was included in the multivariate analysis and was not independently associated with PMV. Its inclusion also did not alter the association between the CVP and PMV.

Preoperative and postoperative pulmonary hypertension have been associated with reperfusion injury and worse outcome after lung transplantation. ${ }^{1,7,19,24,25}$ Pulmonary ar- terial hypertension and right ventricular dysfunction might in part explain the association between the CVP and PMV in our study. Unfortunately, because of inconsistencies in recording, we were not able to include direct measurements of pulmonary artery pressure in our analysis. However, the tight correlation between the CVP and PCWP suggests that there might be many cases in which pulmonary hypertension is secondary to raised left atrial pressure rather than a primary problem with the pulmonary vasculature.

Although numerous articles ${ }^{26-29}$ have reported advantages of the pulmonary vasodilator nitric oxide, a recent randomized trial ${ }^{30}$ did not show significant benefit in prevention of reperfusion injury. However, the use of nitric oxide was not targeted to patients with pulmonary hypertension and increased CVP.

The association between CVP and PMV, even after correcting for mechanical ventilation, poor cardiac function, and high inotrope use, raises speculation as to whether outcome in patients with high CVPs might have been improved by more aggressive application of pulmonary vasodilators, fluid restriction, and diuretics. Demonstrating a reduction in CVP in response to these interventions might identify those likely to obtain the greatest benefit.

There was no evidence that patients with lower CVPs had complications related to hypovolemia. Quite the reverse, patients with a high CVP had increased inotrope requirements and higher serum creatinine levels. This and the trend toward better oxygenation in the low CVP group 
supports the present policy of our unit in aiming for low filling pressures in the early postoperative period.

In conclusion, our study confirms that there is a relationship between a high CVP and an adverse outcome after lung transplantation. This is independent of cardiac function and not caused by the presence of mechanical ventilation. We could find no evidence of complications related to hypovolemia in patients with low CVPs. The CVP remains both a useful hemodynamic marker of the patient's status and a prognostic marker for PMV and poor outcome after lung transplantation. Whether interventions to manipulate CVP affect patient outcome is yet to be determined.

\section{References}

1. King RC, Binns O, Rodriguez F, et al. Reperfusion injury significantly impacts clinical outcome after pulmonary transplantation. Ann Thorac Surg. 2000;69:1681-5.

2. Christie JD, Bavaria JE, Palevsky HI, et al. Primary graft failure following lung transplantation. Chest. 1998;114:51-60.

3. Sleiman C, Mal H, Fournier M, et al. Pulmonary reimplantation response in single-lung transplantation. Eur Respir J. 1995;8:5-9.

4. Khan SU, Salloum J, O'Donovan PB, et al. Acute pulmonary edema after lung transplantation: the pulmonary reimplantation response. Chest. 1999;116:187-94.

5. de Perrot M, Lui M, Waddell TK, Keshavjee S. Ischemia-reperfusioninjury induced lung injury. Am J Respir Crit Care Med. 2003;167: 490-511.

6. Fisher AJ, Donnelly SC, Hirani N, et al. Elevated levels of interleukin-8 in donor lungs is associated with early graft failure after lung transplantation. Am J Respir Crit Care Med. 2001;163:259-65.

7. Boujoukos AJ, Martich GD, Vega JD, Keenan RJ, Griffith BP. Reperfusion injury in single lung transplant recipients with pulmonary hypertension and emphysema. J Heart Lung Transplant. 1997; 16:439-48.

8. Sheridan BC, Hodges TN, Zamora MR, et al. Acute and chronic effects of bilateral lung transplantation without cardiopulmonary bypass on the first transplanted lung. Ann Thorac Surg. 1998;66:1755-8.

9. Ware LB, Golden SA, Finkenbeiner WE, et al. Alveolar epithelial fluid transport capacity in reperfusion lung injury after lung transplantation. Am J Respir Crit Care Med. 1999;159:980-8.

10. Kaplan JD, Trulock EP, Cooper JD, Schuster DP. Pulmonary vascular permeability after lung transplantation. A PET study. Am Rev Respir Dis. 1992;142:954-7.

11. Snell G, Klepetko W. Peri-operative lung transplant management. Eur Respir Mon. 2003;26:130-42.

12. Australian Transplant Coordinators Association. National Guideline for Organ and Tissue Donation-1993. Sydney, Australia: Australian Transplant Coordinators Association Inc; 1993.
13. Steinman TI, Becker BN, Frost AE, et al. Guidelines for the referral and management of patients eligible for solid organ transplantation; Clinical Practice Committee, American Society of Transplantation. Transplantation. 2001;71:1189-204.

14. Esmore DS, Brown R, Buckland M, et al. Techniques and results in bilateral sequential single lung transplantation. J Card Surg. 1994;9: 1-14.

15. Gabbay E, Williams TJ, Griffiths AP, et al. Maximising the utilisation of donor organs offered for lung transplantation. Am J Respir Crit Care Med. 1999;180:265-71.

16. Christie JD, Kotloff RM, Pochettino A, et al. Clinical risk factors for primary graft failure following lung transplantation. Chest. 2003;124: $1232-41$

17. Thabut G, Vinatier I, Stern JB, et al. Primary graft failure following lung transplantation. Predictors of mortality. Chest. 2002;121:1876-82.

18. Chatila W, Satoshi F, Gaughan JP, Criner GJ. Respiratory failure after lung transplantation. Chest. 2003;123:165-73.

19. Sekine Y, Waddell TK, Matte-Martyn A, et al. Risk quantification of early outcome after lung transplantation: donor, recipient, operative and post-transplant parameters. J Heart Lung Transplant. 2004;23:96104.

20. Calvin JE, Driedger AA, Sibbald WJ. Does the pulmonary capillary wedge pressure predict preload in critically ill patients? Crit Care Med. 1981;9:437-43.

21. Biondi JW, Schulman DS, Matthay RA. Effects of mechanical ventilation on right and left ventricular function. Clin Chest Med. 1988;9: 55-71.

22. Schulman DS, Biondi JW, Mathay RA, Zaret BL, Soufer R. Differing responses in right and left ventricular filling, loading and volumes during PEEP. Am J Cardiol. 1989;64:7727.

23. Qvist J, Pontoppidan H, Wilson RS, Lowenstein E, Laver MB. Haemodynamic responses to mechanical ventilation with PEEP; the effect of hypervolemia. Anaesthesiology. 1975;42:45-55.

24. Sommers KE, Griffith BP, Hardesty RL, Keenan RJ. Early allograft dysfunction in twin recipients from the same donor: risk factor analysis. Ann Thorac Surg. 1996;62:784-90.

25. Bando K, Keenan RJ, Paradis IL, et al. Impact of pulmonary hypertension on outcome after single-lung transplantation. Ann Thorac Surg. 1994;58:1336-42.

26. Date H, Triantafillou AN, Trulock EP, Pohl MS, Cooper JD, Patterson GA. Inhaled nitric oxide reduces human lung allograft dysfunction. J Thorac Cardiovasc Surg. 1996;111:913-9.

27. Ardehali A, Laks H, Levine M, et al. A prospective trial of inhaled nitric oxide in clinical lung transplantation. Transplantation. 2001;72: $112-5$.

28. Meyer KC, Love RB, Zimmerman JJ. The therapeutic potential of nitric oxide in lung transplantation. Chest. 1998;113:1360-71.

29. Thabut G, Brugere O, Leseche G, et al. Preventative effect of inhaled nitric oxide and pentoxyfilline on ischaemia/reperfusion injury after lung transplantation. Transplantation. 2001;71:1295-300.

30. Meade M, Granton JT, Matte-Martyn A, et al. A randomized trial of inhaled nitric oxide to prevent reperfusion injury following lung transplantation. Am J Respir Crit Care Med. 2003;167:1483-9. 